\title{
Total Body Clearance for Dose Interval Normalized by Weight
}

National Cancer Institute

\section{Source}

National Cancer Institute. Total Body Clearance for Dose Interval Normalized by Weight. NCl Thesaurus. Code C114233.

The total body clearance for intravascular administration for dose interval divided by the weight. 